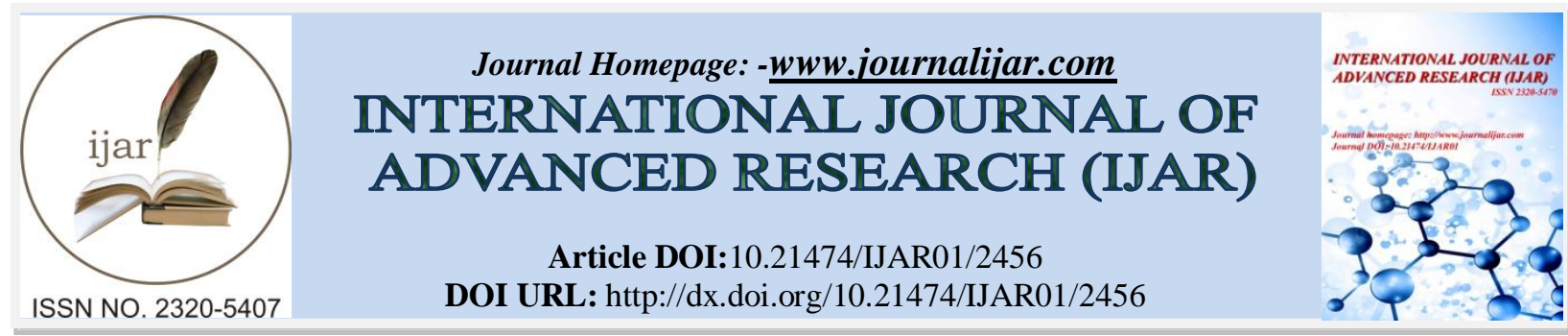

RESEARCH ARTICLE

\title{
THE PREVALENCE AND ATTITUDE OF EAR NOSE THROAT (ENT) INFECTIONS\PROBLEMS AMONG MEDICAL STUDENTS, TAIBAH UNIVERSITY, AL-MADINAH AL-MUNAWARA, KINGDOM OF SAUDI ARABIA (KSA), 2016.
}

\section{"Mariam JaberAlatowiAljehani ${ }^{1}$, Sarah Khaled Alrasheed ${ }^{1}$, Hatem Mohammed Ahmed ${ }^{1}$ and Nahid Ebrahim Fallatah' ${ }^{2}$.}

1. Medical intern, Taibah University.

2. Family Medicine Consultant, Taibah University.

\section{Manuscript Info}

[.........................

Manuscript History

Received: 20 October 2016

Final Accepted: 22 November 2016

Published: December 2016

Key words:-

Ear, Nose, Throat, Infections, Attitude,

Prevalence.

\section{Abstract}

Background/Aims: Ear, nose and throat diseases are major public health concerns with increased morbidity and mortality. This study aims to identify the prevalence of ear, nose and throat infectionslproblems among medical students in Taibah University, Madina, KSA, 2016.

Methods: A Cross sectional survey using an electronic selfadministered questionnaire in English. It was sent to a random sample of (288) medical students male and female, Taibah University Madinah, Saudi Arabia. The results were tabulated and analyzed by using SPSS version 20.

Results: A total 289 of medical students responded to our questionnaire, the students were within the age range of 18-25 years, with total mean age of both sex 23 years, and most of the participants were females $(55.0 \%)$. we reported high prevalence of ENT problems among them, which was 257 (91,7). Also, we found that most of the respondents complained of throat infection alone (54.7\%). nearly we found a relation between the prevalence of throat, nose and ear infection lproblems to the area of residency and gender.

Conclusions: The ear, nose and throat problemslinfections occur frequently and widely among them. The most prevalent complain of the respondents with ear, nose and throat disorder was throat infection alone. The majority of participants received antibiotics prescriptions from doctors, and most of them visited the emergency department due to ear, nose and throat problems.

Copy Right, IJAR, 2016,. All rights reserved.

\section{OBJECTIVES}

General objectives: -

1. To estimate the prevalence of (ENT) infections lproblems among Taibah University Medical students including Medical interns

2. To assess the attitude that used by medical students to ward their Ear, Nose, and Throat infections Iproblems. 


\section{Specific objectives: -}

1. To identify the main complaints of (ENT) infections \problems among Taibah University Medical students.

2. To know the frequency of (ENT) infections Iproblems per year among them.

\section{Introduction: -}

ENT is a part of medicine that deals with ear, nose and throat disorders. However, ENT diseases are serious public health problems with universal distribution affecting all age groups [1,2]. Although, ear, nose and throat diseases are very important because of the type of morbidities, which may lead to impairment of the physiological functions. These include problems of hearing, breathing, swallowing, phonation, speech, olfaction, taste, and protection of the lower respiratory tract and clearance of secretions [4,5]. Globally, Ear infections considered as one of the leading causes of health care visits and its complications represent important causes of preventable hearing loss, especially in developing countries [1]. While around $0.5 \%$ of all upper respiratory tract infections are complicated by sinusitis, the incidence in UK of acute sinusitis ranges from 15 to 40 episodes per 1000 patients per year and it is the secondmost common infectious disease seen by general physicians [2]. However, acute throat infections are the most common infectious diseases seen by family physicians and they are responsible for $2 \%$ to $4 \%$ of all visits $[4,5]$. Regarding The prevalence of ear, nose and throat problems in the community, it appears that ENT disorders occur frequently in society. Therefore, ENT diseases may lead to various types of complications that affect daily life activity such as, hearing loss, obstructive sleep apnea and cardiopulmonary complications. Philip C Hannaford et al, conducted a study at Scotland in 2005. A total of 15,788 individuals aged over 14 years were participated in the study, they reported the incidence of ear, nose and throat symptoms, participants' sociodemographic characteristics and epidemiological distributions. 50\% of respondents reported currently having hearing difficulties, while between $13 \%$ and $18 \%$ of respondents reported persistent nasal symptoms and hay fever, respectively. However, $31 \%$ had at least one episode of severe sore throat or tonsillitis and nearly $29 \%$ experience unsteadiness, light-headedness or feeling faint. Based upon research, ENT symptoms common among community with variations according to age, gender and occupations, however most of these affected participants manage their ENT problems without consulting the health services [7]. Ayotunde et al, (Nigeria, 2013) reported the prevalence of ear, nose and throat diseases and its related complication. 58\% of the adult patients presented with ear disorders of which $34.5 \%$ were cases of hearing loss while, Rhinosinusitis was the second most predominant ear, nose and throat disorders among adult patients [1,9]. In addition, a total of 1047 patients came to ENT HAJJ clinic, Saudi Arabia, 85.5\% were diagnosed of upper respiratory tract infections including pharyngitis, viral upper respiratory tract infection and tonsillitis, $24 \%$ of them were admitted with average admission rate of 2 patients per day and $94 \%$ of them received antibiotics as part of their main therapy according to Ameen Z.Alherabi (KSA, 2008) [14].

Regarding general attitude toward ear, nose and throat problems, Dilys Addeyand Adrian Shephard showed that majority of participants stating that they tend to see how symptoms develop and if they don't disappear quickly, they take appropriate medications. Only a small proportion of respondents prefer to avoid medication and just get on with life, putting up with the discomfort. While, respondents suffering from throat discomfort caused by perceived bacterial or viral infection or cold or influenza were most likely to use medicated products which contain a medicinal substance or active ingredient, hot drinks, throat sweets, or consult a GP. Those suffering from hay fever or allergy most frequently consulted a GP or took medicated products. There was also a tendency for respondents who suffered a higher degree of perceived discomfort and those who had suffered for longer periods ( $>4$ days) to use medicated treatments (UK, France, Poland, and Malaysia, 2013) [10,13]. According to Philip C Hannaford et al, (Scotland, 2005), 23\% with hearing problem who ever visited the general physician while $38 \%$ with sever sore throat or tonsillitis and only $16 \%$ with nose problem [11]. Although, the most frequently observed symptoms leading to the emergency room consultation were: pain, sudden loss of hearing, bleeding, a swallowed foreign body while, The most frequent nasal sign was epistaxis, the most frequent auditory condition was acute external and middle ear otitis, and the most frequent pharyngeal condition was ingestion of a foreign body among 20.563 adult patients attended the ENT emergency clinic over 18 months (Timsit CA et al, France , 2001) [8]. Due to lack of researches in our region, we need more studies to evaluate the prevalence of ear nose throat diseases and patients' attitude towards illness as it has been considered as a rapidly escalating public health problem affecting various populations with different age groups. The aim of this study is to estimate the prevalence of (ENT) diseases and to assess the altitude that used by medical students to ward their Ear, Nose, and Throat problems among medical students, Taibah University, Al-Madinah Al-Monawara In Kingdom of Saudi Arabia, 2016. 


\section{Methodology: -}

Aim of study: The aim of study to identify the prevalence of Ear, Nose and Throat infectionslproblems among medical students in Al-Madinah Al-Monawara, KSA, 2016. The study Was conducted during the period from (September to October, 2016).

Study area: The study area will be carry out in the medical college, Al Madinah AL-Monawara, Taibah University, Kingdom of Saudi Arabia. A Taibah University which is situated in the City of Medina, Kingdom of Saudi Arabia where our Prophet Mohammed (Peace be upon him). Taibah university consists of several college one of them is medical college, being the first medical college in AL-Madinah Al-Monawara, the medical college was established as the beginning of «Faculty of Medicine and Medical Sciences»."

Study design $\backslash$ population: A Cross sectional survey will be carry out in the medical college; male and female sections, Al Madinah AL-Monawara, Taibah University, Saudi Arabia, 2016.

Sample size Isample technique: A convenience sample of (288) medical students of Taibah University throughout Al-Madinah Al-Monawara, KSA, 2016.

Data collection tools and techniques: using electronic self-administered questionnaire in English Google form. The results will be tabulated and analyzed by using SPSS version 20. We will carry out the pilot of study on 15 members of medical students to detect if there is any difficulty of answering, and these members are not included in our study. The pilot questionnaire will be corrected by ENT specialist.

Benefit of the study: A lot of heath care units can utilize the results of the study in raising the awareness about the diseases associates with higher serum lipids especially in Saudi Arabia population, also, the results can alert the individuals who are at risk for elevation of serum lipid to rectify the problem by healthy lifestyle choices.

Conflict of interest and funding: The investigators have no conflict of interest. They have not received any research grant from any company or organization for this project.

Ethical consideration: Ethical approval to conduct the study will be obtained from the right ethical committee of medical College (REC-CM), Taibah University. All human subjects research carried out in college of medicine, Taibah University, must be reviewed and approved prior to the involvement of human subjects in research. Ethical consideration will be considered. Privacy and confidentiality are assuring. electronic consent was obtained from every participant after explanation of the objective and methodology of the study.

\section{Results: -}

By the end of the survey period, data had been collected from 289 individuals, one hundred and twenty-nine (44\%) of whom were men and one hundred fifty-nine (55\%) were women. The students were within the age range of 18-25 years old, with total mean age of both sexes 23 years old, and the majority of the participants were females $(55.0 \%)$ as shown in Figure1. Interestingly, a high prevalence of ENT problems was observed among those who completed our questionnaire, 257 (91, 7\%).Also, what stands out in figure 1 is the high prevalence of throat infection alone (54.7\%). We found a positive correlation between the prevalence of throat, nose and ear diseases and the area of residency.As can be seen from Table 1 and Figure 2, a high prevalence of ENT diseases reported significantly more in urban residents. Generally, students with ear diseases were $123(42.6 \%)$, the nose diseases were reported in $173.0(59.9 \%)$ and those with throat diseases were 271.0 (93.8\%) and their associations with gender are illustrated in Table 2. Approximately ninety three percent of respondents reported having the attack of throat infection, most of them (59\%) have this attack once to two times per year and while only six percent rarely complain of throat infection as depicted in figure 2. Regarding those who reported having throat infection, throat pain was the most common symptom as reported bya total of $227(78 \%)$, and the least common symptom during throat infection attack was fever with only (48\%) as set out in Table 3. Twenty-six (9\%) of participants underwent tonsillectomy, and in most of them it was done between the age of three to six years old (13\%). We found no specific relation between participants who had their tonsils removed and recurrent throat infection, as seen in Table 4. Furthermore, we reported that $173(59.9 \%)$ of respondents developed nose infection symptoms, while 116(40.1\%) did not usually suffer from nose infection. Most common symptoms reported among them was nasal discharge in (40.5\%), and the least common one was fever (18.3\%) as in Figure 2. Nearly $4.8 \%$ of participants had their adenoids removed, and in most of them it was done between the age of three and six years old as in Figure 3. In addition, a total of 30.8\% of 
participants had nasal epistaxis attack while $61.6 \%$ did not suffer from this as illustrated in Figure 5 and Table 5. Moreover, about 123 individuals (42.6\%) had ear infection, most of them (96) developed this attack once to two times per year as shown in Figure 6. It can be seen from the data in Table 6 that most of them (32.9\%) complained of ear pain. According to the attitude of participants towards their ENT problems as presented in Table 7, approximately $45.5 \%$ of participants received their antibiotics prescriptions from doctors. In the other hand, about $32 \%$ of respondents managed their ENT symptoms by taking over the counter drugs or other medications including prescribed antibiotics from home. And a minority about 4.5\% did not do anything regarding their illness. Also, around 75 individuals $(26 \%)$ visited the emergency department due to ENT problems linfection, and most of them $(16.6 \%)$ did that because their symptoms lasted more than one day, and only $1 \%$ of them sought medical help in the ER because they noticed discharges as set out in Table 8.

\section{Discussion: -}

An ample variation between the prevalence of ENT disorders and attitude was recognized in this study. We found a high prevalence of ENT problems among 257 respondents (91,7\%). And the most common complain among all ENT disorders was throat infection alone. As mentioned before, the prevalence of throat problems was 271.0 (93.8\%), nose problems 'prevalence was 173.0 (59.9\%), and the prevalence of ear problems was $123(42.6 \%)$. Comparatively, these results are contrary to data obtained in a study conducted in Hospital \& University of Ibadan, Nigeria. In this study the prevalence of throat diseases was 479 (9.6\%), Nose disorders' prevalence was 1153 $(23.0 \%)$, and the prevalence of ear problems was $3136(62.7 \%)$ [1]. This discrepancy could be attributed to differences of hygiene level, degree of temperature and personal habit. Regarding ear disorders, a Scottish study reported that most of the participants $(32.9 \%)$ complained of ear pain, but (9\%) complained of diminished hearing. This study had a wide range of age and showed a high prevalence of hearing loss among men aged above 75 years old [11]. According to nose diseases, an international longitudinal research which was a community-based study of more than 11000 individuals aged 20-44 years old from 14 countries in Europe and America found persistent nasal discharge was the most common nasal symptom [13]. This inconsistency may be due to the narrow range of age that we used in our study. Concerning, the attitude of respondents in our study towards ENT problems, around $26 \%$ of them visited the emergency department, most of them (16.6\%) did that because they noticed a discharge. However, In a study conducted in Nottingham, $18 \%$ of respondents visited their GP in the previous two years for hay fever, but in a Scottish study, $17 \%$ of respondents visiting their GP for nasal problems $[11,12]$.

\section{Limitations: -}

The generalizability of these results is subject to certain limitations. For instance, inclusion of a greater number of participants was not feasible. Also, inability to obtain a detailed history that measures severity of symptoms, their effect on quality of life, and potential risk factors such as smoking, allergy, close contact with infected patients and other occupational hazards. More in-depth study of participants' knowledge about ENT diseases and considering socioeconomic and demographic aspects would be undoubtedly advantageous to get a fuller understanding of patterns of help-seeking behavior. Furthermore, the scope of this study was limited in terms of its external validity. The methodology that was implemented in data collection yielded qualitative data that only can be interpreted relative to participants' populations.

\section{Conclusions: -}

Ear, nose and throat infections Iproblems occur widely among study's participants. The most prevalent complain of the respondents with ear, nose and throat disorder was throat infection alone. The majority of participants received antibiotics prescriptions from doctors, and most of them visited the emergency department due to ear, nose and throat problems.

\section{Recommendations: -}

A high prevalence of ENT diseases among medical students necessitates a larger exploit for media in spreading awareness about this issue. Since many ENT diseases are infectious, and hence could be preventable by variable means which include: 1- Students must understand their responsibilities to protect themselves as individuals and their responsibilities to protect patients from the hazards of infectious diseases. 2- The university and the individual student have a duty of care towards both students and patients to minimize the risk of spreading or contracting infectious or air-borne diseases. 3- The university has a legal duty to ensure the safety of students and patients. If a student or patient is knowingly or unknowingly infected during the course of a student's clinical experience, the university may be held legally liable. It is not sufficient to have infectious diseases policies in place; it is necessary 
to ensure programs are implemented and that students comply. 4- Students are responsible for understanding and practicing infection control practices, including standard and additional precautions, in their clinical experiences. 5Implementation for an immunization program including vaccinations and related tests for specified infectious diseases are a must. 6-Medical students have an ethical duty to be aware of their immunity or infectious status to ensure they do not place others at risk of infection. 7- promote the concept of health seeking behavior among medical students towards ENT diseases and infections by getting contact with specialized otolaryngologists, in despite of having a background of the illness. Ultimately, we encourage to conduct further studies on the same subject to include all medical students in all over the Kingdom of Saudi Arabia.

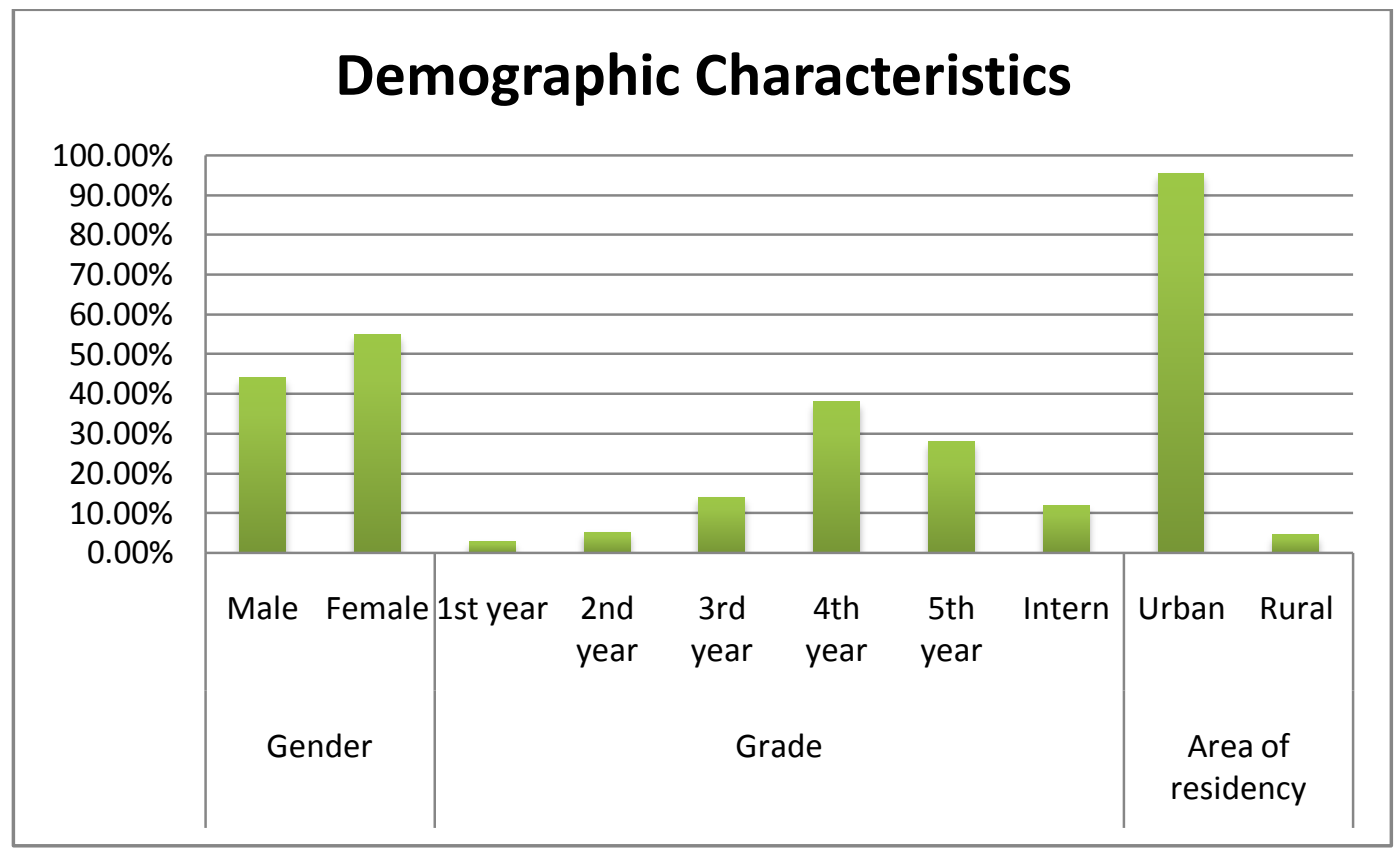

Figure (1):- Demographic Characteristics.

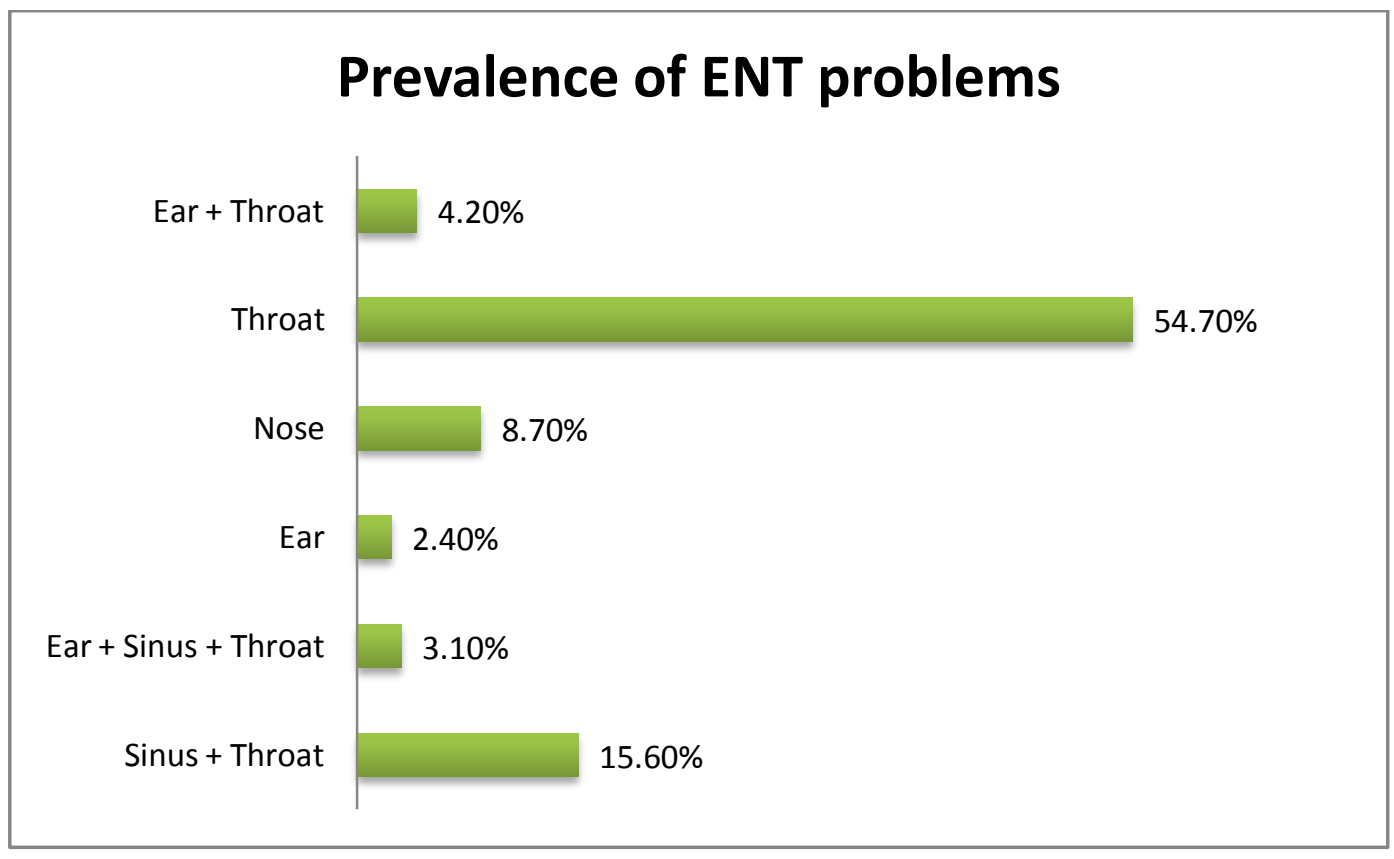

Figure (2):- Prevalence of ENT problems among medical participants. 


\section{Frequency of throat infection per year}

More than 5

times per year

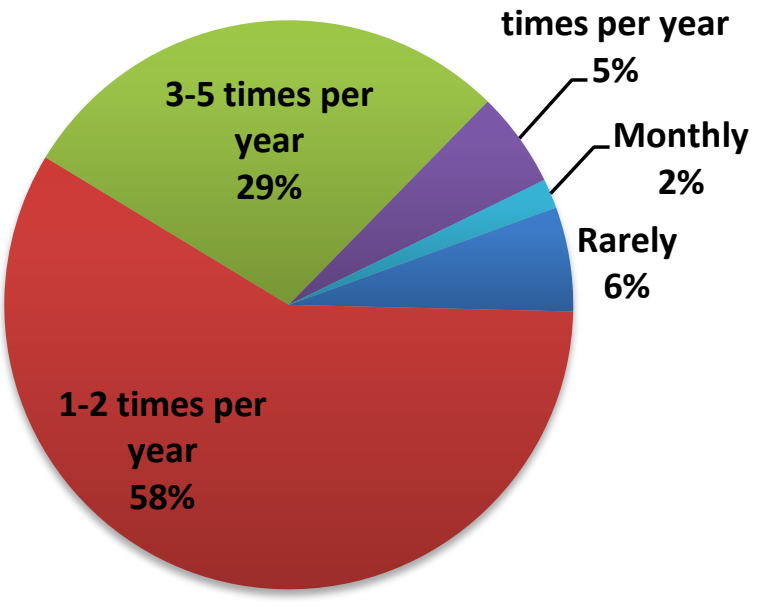

Figure (3):- Frequency of throat infection per year.

\section{Frequency of nose infection per year}

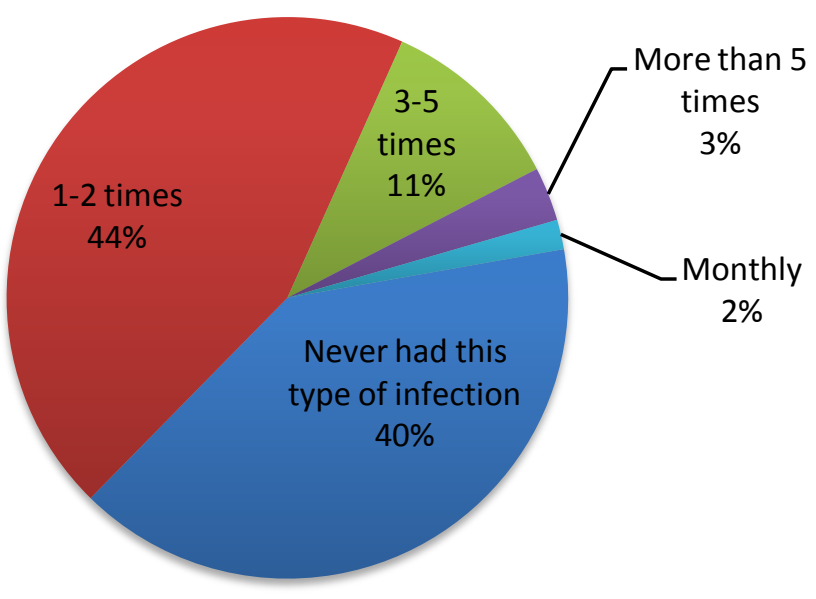

Figure (3):- frequency of nose infection per year 


\section{Frequency of ear infection per year}

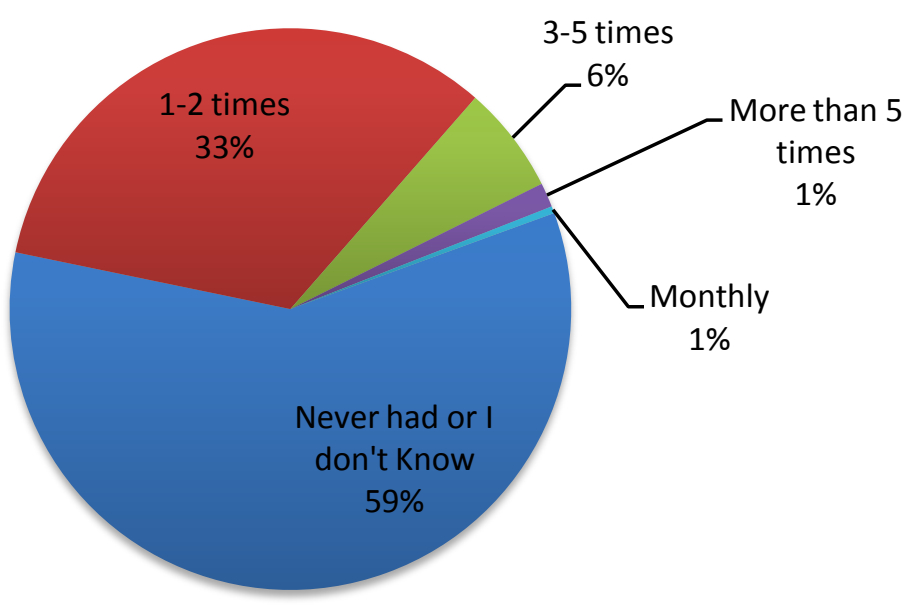

Figure (5):- Frequency of ear infection per year.

\begin{tabular}{|l|l|l|l|}
\hline & Rural & Urban & Total \\
\hline Ear diseases & $1.7 \%$ & $40.8 \%$ & $42.6 \%$ \\
\hline Nose diseases & $2.8 \%$ & $57.1 \%$ & $59.9 \%$ \\
\hline Throat diseases & $4.5 \%$ & $89.3 \%$ & $93.8 \%$ \\
\hline ENT diseases & $9 \%$ & $82,2 \%$ & $91,2 \%$ \\
\hline
\end{tabular}

Table (1):- Relation of the prevalence of ENT diseases and the area of residency

$($ Chi-Square $=.670$ ' $\mathrm{p}$-value $=.496$ )

\begin{tabular}{|l|l|l|l|}
\hline & Male & Female & Total \\
\hline Ear diseases & $19 \%$ & $23.5 \%$ & $42.6 \%$ \\
\hline Nose diseases & $27.3 \%$ & $32.5 \%$ & $59.9 \%$ \\
\hline Throat diseases & $41.5 \%$ & $52.2 \%$ & $93.8 \%$ \\
\hline ENT diseases & $9 \%$ & $82,2 \%$ & $91,2 \%$ \\
\hline
\end{tabular}

$($ Chi-Square $=.810 ' \mathrm{p}$-value $=.435)$

Table (2):- Relationship of gender with of ENT diseases

\begin{tabular}{|l|l|l|}
\hline Type of symptoms & Percentage & Frequency \\
\hline Fever & 141 & 48.8 \\
\hline Throat pain & 227 & 78.5 \\
\hline Swallowing pain & 70.6 & 204 \\
\hline Cough & 176 & 60.9 \\
\hline Runny nose & 65.1 & 188 \\
\hline
\end{tabular}

Table (3):- Distribution of respondents by type of throat symptoms

\begin{tabular}{|l|l|l|l|}
\hline Remove the tonsil & Recurrent throat infection & No recurrent throat infection & total \\
\hline No & $85.5 \%$ & $5.5 \%$ & $91.0 \%$ \\
\hline Yes & $8.3 \%$ & $0.7 \%$ & $9.0 \%$ \\
\hline Total & $93.8 \%$ & $6.2 \%$ & $100.0 \%$ \\
\hline
\end{tabular}

Table (4):- Relation between tonsillectomy and recurrentthroat infection

$($ Chi-Square $=0.670$, P-value $=0.496)$ 


\begin{tabular}{|l|l|l|}
\hline Type of symptoms & Frequency & Percent \\
\hline Fever & 53 & $18.3 \%$ \\
\hline Facial pain & 89 & $30.9 \%$ \\
\hline Nasal discharge & 117 & $40.5 \%$ \\
\hline Loss of smell & 68 & $23.5 \%$ \\
\hline Nasal stiffness & 87 & $30.1 \%$ \\
\hline Cough & 93 & $32.2 \%$ \\
\hline Nasal epistaxis & 89 & $30.9 \%$ \\
\hline
\end{tabular}

Table (5):- Distribution of respondents by type of nose symptoms

\begin{tabular}{|l|l|l|}
\hline Type of ear symptoms & Frequency & Percent \\
\hline Fever & 26 & $9 \%$ \\
\hline Ear pain & 95 & $32.9 \%$ \\
\hline Ear discharge & 20 & $6.9 \%$ \\
\hline Headache & 67 & $23.2 \%$ \\
\hline Sense of rotation & 25 & $8.7 \%$ \\
\hline Loss of appetite & 13 & $4.5 \%$ \\
\hline Sleeping difficulties & 41 & $14.2 \%$ \\
\hline Diminished hearing & 26 & $9 \%$ \\
\hline
\end{tabular}

Table (6):- Distribution of respondents by type of ear symptoms

\begin{tabular}{|l|l|l|}
\hline How manage their ENT problem & Frequency & Percent \\
\hline no thing & 13 & 4.5 \\
\hline medication from pharmacist & 55 & 19.0 \\
\hline medication from home & 95 & 32.9 \\
\hline go to hospital & 61 & 21.1 \\
\hline supportive care & 65 & 22.5 \\
\hline Total & 289 & 100.0 \\
\hline
\end{tabular}

Table (7):- Respondents' attuited towards ENT diseases

\begin{tabular}{|l|l|l|}
\hline & Frequency & Percent \\
\hline Symptoms last more than one day & 48 & $16.6 \%$ \\
\hline Symptoms does not resolve & 36 & $12.5 \%$ \\
\hline Fever & 32 & $11-1 \%$ \\
\hline Observe discharge & 3 & $1 \%$ \\
\hline
\end{tabular}

Table (8):- Reasons of visited emergency department due to ENT problems

\section{Acknowledgement: -}

At the outset, we would like to express our deep and sincere gratitude to the following people without whose support this research project would not have been a success. We would like to sincerely thank Dr. Rayan Al-Hussini, Otolaryngologist-head and neck surgeon, Ohoud hospital, Madina, for offering valuable advices and wise counsel, and for his availability for a genuine guidance. We also owe our gratitude to Taibah University for facilitating our study by providing a suitable environment and encouraging us from the beginning up to this far. We are indebted and grateful to all the medical students and interns who participated in this study. Finally, we are extending our thanks to everyone who has supported us to complete the research work directly or indirectly

\section{Reverences: -}

1. Ibekwe TS, Nwaorgu OGB, Onakoya PA, Ibekwe PU. Spectrum of Otorhinolaryngological emergencies in elderly in Ibadan, Nigeria. Nig J Med. 2005; 14(4):411-414.

2. Kishve SP, Kumar N, Kishve PS, Aarif SMM, Kalakoti P. Ear, Nose and Throat disorders in paediatric patients at a rural hospital in India. Australasian Medical Journal AMJ. 2010; 3(12):786-790.

3. Monasta L, Ronfani L, Marchetti F, et al; Burden of disease caused by otitis media: systematic review and global estimates. PLoS One. 2012;7(4): e36226. Epub 2012 Apr 30. 
4. McCormick A, Fleming D, Charlton J. Morbidity statistics from general practice-fourth National Morbidity Survey 1991-92. London, UK: HMSO, Office for National Statistics; 1995.

5. Kirkwood CR, Clure HR, Brodsky R, Gould GH, Knaak R, Metcalf M, et al. The diagnostic content of family practice: 50 most common diagnoses recorded in the WAMI community practices. J Fam Pract. 1982;15(3):485-92.

6. Taibah university, college of medicine, establishment ,2003, URL: https://www.taibahu.edu.sa/Pages/EN/Sector/SectorPage.aspx?ID=29

7. Hannaford PC1, Simpson JA, Bisset AF, Davis A, McKerrow W, Mills R, Theprevalence of ear, nose and throat problems in the community: results from a national cross-sectional postal survey in Scotland,FamPract. Jun;22(3):227-33. Epub 2005, Mar 16.

8. Timsit CA, Bouchene B, Olfatpour PH, Herman p, Tran Ba Huy. Epidemiology and clinical findings in 20563 patietns attending the Lariboisiere Hospital ENT adult emergency clinic. Annals D'otolaryngologie Et De ChirurgieCervico-Faciale; 2001; 118 (4): 215-222,2001.

9. Ayotunde James Fasunla1,\&, Musa Samdi1, Onyekwere George Nwaorgu1,An audit of Ear, Nose and Throat diseases in a tertiary health institution in South-western Nigeria,PanAfr Med J. 14:1. doi: 10.11604/pamj,Epub 2013.

10. T Sing, Pattern of Otorhinolaryngology Head and Neck Diseases in Outpatient Clinic of a Malaysian hospital, The Internet Journal of Head and Neck Surgery, Volume 2 ,Number1.,2001.

11. Philip C Hannaford, Julie A Simpson, Ann Fiona Bisset,Adrian Davis, William McKerrow and Robert Mills, The prevalence of ear, nose and throat problems in the community: results from a national cross-sectional postal survey in Scotland, Family Practice - an international journal , 16 March 2005

12. Ayotunde James Fasunla1,\&, Musa Samdi1, Onyekwere George Nwaorgu1, An audit of Ear, Nose and Throat diseases in a tertiary health institution in South-western Nigeria , P an African Medical Journal - ISSN: 19378688.

13. Jones NS, Smith PA, Carney AS et al. The prevalence of allergic rhinitis and nasal symptoms in Nottingham. Clin Otolaryngology Allied Sci 1998; 23: 547-554.

14. AmeenZalhaerabi, road map of Ear, Nose, Throat clinic during 2008 hajj in makkah ,Saudi Arabia, Saudi med J,volum 30 (12), 2009, 